\title{
The Characteristics of Women with Subsequent Distal Radius Fracture after Initial Distal Radius Fracture
}

\author{
Jongjin Lee', Jae Kwang Kim', Minyoung Oh², Young Ho Shin ${ }^{1}$ \\ 'Department of Orthopedic Surgery, Asan Medical Center, University of Ulsan College of Medicine, Seoul; \\ ${ }^{2}$ Department of Nuclear Medicine, Asan Medical Center, University of Ulsan College of Medicine, Seoul, Korea
}

\author{
Corresponding author \\ Young Ho Shin \\ Department of Orthopedic Surgery, Asan \\ Medical Center, University of Ulsan College of \\ Medicine, 88 Olympic-ro, 43-gil, Songpa-gu, \\ Seoul 05505, Korea \\ Tel: +82-2-3010-1838 \\ Fax: +82-2-488-7877 \\ E-mail: 123sinyh@gmail.com
}

Received: December 30, 2020

Revised: February 7, 2021

Accepted: February 28, 2021
Background: The purpose of this study was to investigate the characteristics of women with subsequent distal radius fracture (DRF) and to compare bone fragility variables in women with initial and subsequent DRF. Methods: We enrolled 227 women who experienced DRF (203 women with initial DRF and 24 women with subsequent DRF) between September 2016 and April 2019. We compared demographic characteristics and bone fragility variables, including bone mineral density, trabecular bone score, hip geometry, bicortical thickness of the distal radius, and fracture risk assessment tool (FRAX) scores between the 2 groups. To reduce bias, patients with subsequent DRF were propensity score-matched in a 1:2 manner with patients affected by initial DRF, and additional comparisons were performed. Results: Patients in the subsequent DRF group were older than those in the initial DRF group, but this difference was not significant $(P=0.091)$. The proportion of patients receiving treatment with osteoporosis medication was significantly higher in the subsequent DRF group $(41.7 \%$ vs. $19.2 \%, P=0.011)$. Bone fragility variables did not differ significantly between the 2 groups. However, the ten-year probability of major osteoporotic fractures based on FRAX scores was significantly higher in patients with subsequent DRF $(7.5 \%$ vs. $10.8 \%, P<0.001)$. Similar results were observed when comparing the propensity score-matched initial and subsequent DRF groups. Conclusions: These findings suggest that the occurrence of subsequent DRF after initial DRF can be attributed to multiple factors rather than bone fragility alone. Systematic and multidisciplinary management would be helpful in preventing the occurrence of subsequent DRF after the initial DRF.

Key Words: Bone density · Hip geometry · Osteoporosis · Radius fractures · Trabecular bone score

\section{INTRODUCTION}

\section{Mineral Research}

This is an Open Access article distributed under the terms of the Creative Commons Attribution Non-Commercial License (https://creativecommons.org/licenses/by-nc/4.0/) which permits unrestricted non-commercial use, distribution, and reproduction in any medium, provided the original work is properly cited.

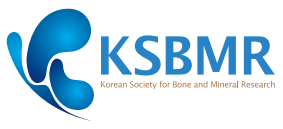

The purpose of osteoporosis evaluation and management is to prevent the occurrence of osteoporotic fractures. This concept is most applicable to patients who have already experienced an osteoporotic fracture, as these patients are at higher risk of subsequent osteoporotic fracture.[1,2]

Distal radius fracture (DRF) is the most common upper extremity fracture in women aged $\geq 50$ years,[3] and the occurrence of DRF is considered indicative of bone 
fragility.[2,4] The risk of future fractures at multiple sites, especially the hip and spine, has been reported to be higher in patients who have experienced wrist fractures than those who have not.[2,5-7] In addition, the wrist has been reported to be the most vulnerable site for subsequent fracture after initial wrist fracture, with the risk of subsequent wrist fracture being higher than the risk of hip fracture after an initial wrist fracture.[6] However, to date, the characteristics of patients with subsequent DRF after initial DRF have not been determined.

Bone mineral density (BMD) has been widely used for diagnosing bone fragility and is currently used as a parameter for diagnosing osteoporosis. However, because BMD does not always reflect fracture risk, other bone fragility parameters, such as trabecular bone score (TBS), hip geometry parameters, and cortical thickness of long bones, have been evaluated.[8-10] In addition, the fracture risk assessment tool (FRAX) was developed to reflect the clinical situation of the patients.[11] To our knowledge, these bone fragility parameters have not been evaluated in patients with subsequent DRF.

The present study was designed to investigate the characteristics of patients with subsequent DRF after initial DRF. In addition, bone fragility parameters were compared in patients with initial and subsequent distal radius fractures to identify the factors contributing to the occurrence of subsequent DRF.

\section{METHODS}

\section{Study population}

The protocol used for this cross-sectional, retrospective review of medical records was approved by the institutional review board of our institute. We enrolled women who experienced a DRF between September 2016 and April 2019 and met the following inclusion criteria: (1) acute DRF caused by minor trauma, such as a fall from standing height; and (2) performed a dual energy X-ray absorptiometry (DXA; Lunar Prodigy Advance; GE Lunar, Madison, WI, USA) within 2 weeks after diagnosis of the fracture. The exclusion criterion was DRF by major trauma such as traffic accidents. An osteoporosis examination is routinely recommended by a treating orthopedic surgeon for all patients with DRF on their first follow-up visit to the outpatient clinic or after admission for operation. Finally, 227 women who met the criteria were enrolled. The mean age of the cohort was $65.1 \pm 10.1$ years, mean body mass index (BMI) was $23.4 \pm$ $3.1 \mathrm{~kg} / \mathrm{m}^{2}$, and 163 patients ( $71.8 \%$ of 227 patients) were treated surgically.

Among the 227 patients with DRF, 203 experienced a first-time DRF (initial DRF group) and 24 had a previous history of DRF (subsequent DRF group). The demographic characteristics, osteoporosis treatment history, and bone fragility parameters, including BMD, TBS, hip geometry parameters, bicortical thickness (BCT) of the distal radius, and FRAX scores, were compared between the 2 groups. To reduce bias, patients in the subsequent DRF group were propensity score-matched at a 1:2 ratio with patients in the initial DRF group, and additional comparison was performed between these groups. The propensity score was calculated for each patient based on logistic regression analysis, using patient age and BMI for matching.

\section{BMDs and TBS}

At our institute, BMD $\left(\mathrm{g} / \mathrm{cm}^{2}\right)$ was measured in the lumbar spine, femoral neck, trochanter, Ward's triangle, and the total hip using Lunar Prodigy DXA scans (GE Lunar) and was analyzed using Encore Software ver.11.0. The lowest BMD T-score was derived from the BMDs of the lumbar spine, total hip, and femoral neck only, in accordance to the classification proposed by the World Health Organization (WHO).[12] Osteoporosis was defined as the lowest BMD T-score $<-2.5$. The BMD precision errors (percentage of the coefficient of variation) - measured by assessing 30 individuals with 2 scans at our institution-were $1.9 \%$ for the lumbar spine, $2.5 \%$ for the femoral neck, and $1.8 \%$ for the total hip. The least significant changes in BMD, calculated as $2.77 \times$ precision error and at a $95 \%$ confidence level, were $0.053 \mathrm{~g} / \mathrm{cm}^{2}$ for the lumbar spine, $0.069 \mathrm{~g} / \mathrm{cm}^{2}$ for the femoral neck, and $0.050 \mathrm{~g} / \mathrm{cm}^{2}$ for the total hip. For the lumbar spine BMD, the L1-4 value was used for analysis. All TBS measurements were performed retrospectively using TBS iNsight Software, version 3.02 (Med-Imaps, Needham, MA, USA) based on spine DXA files from the database to ensure that the investigators are blinded to all clinical parameters. The software uses the raw DXA images of the anteroposterior spine for the same region of interest as the lumbar spine BMD measurements. 


\section{Hip geometry parameters}

Geometric bone structure properties in all scans were further analyzed using the advanced hip assessment (AHA) program included with the GE Lunar Prodigy software, as described previously.[13,14] The AHA program automatically sets the region of interest, defined as the narrow neck (NN), transversing the narrowest width of the femoral neck. The AHA program yielded data for hip axis length (HAL), neck shaft angle (NSA), mean cortical thickness (mm), femur neck width $(\mathrm{mm})$, cross-sectional area, cross-sectional moment of inertia $\left(\mathrm{cm}^{4}\right)$, section modulus $\left(\mathrm{cm}^{3}\right)$, and buckling ratio at the NN. The short-term coefficients of variance of AHA indices calculated from the images used for the precision assessment of BMD appeared to be slightly greater than those of conventional BMD, but were approximately $2 \%$, similar to the previously reported precision data.[15]

\section{Cortical thickness of the distal radius}

Cortical bone thickness was measured and analyzed based on a previously described method of analyzing the relationship between the BMD and cortical thickness of the distal radius.[16] In patients with initial DRF or recurrent DRF on the same side, an image of the contralateral side was selected. In patients with subsequent DRF on the side contralateral to that of the previous DRF, an old DRF side image was selected. In patients with bilateral subsequent DRF, an image of the dominant hand was selected. All images were randomly sorted after removing the personal information of patients and were reviewed by 1 orthopedic surgeon and 1 orthopedic resident. All radiographic measurements were performed using the picture archiving and communication systems program of our institute (PetaVision; Asan Medical Center, Seoul, Korea). Varying image magnification was normalized by standardizing longitudinal capitate lengths on all radiographs to $21.65 \mathrm{~mm}$.[17] BCT was measured 50 and $70 \mathrm{~mm}$ proximal to the distal radio-ulnar joint, with the mean of the 2 measurements defined as average $\mathrm{BCT}$. The mean value of each measurement was used for the analysis.

\section{FRAX}

FRAX ${ }^{\circledR}$ is a simple fracture risk assessment tool developed by the WHO.[11] FRAX algorithms calculate the 10-year probability of major osteoporotic fractures and hip fractures. We calculated the 10-year probability of fracture by including clinical risk factors such as previous fracture, hip fracture in parents, smoking habits, steroid medicine, rheumatoid arthritis, secondary osteoporosis, and alcohol habits. FRAX scores were acquired using the web-based calculation tool for Korean. We adjusted the FRAX score with TBS in each patient.

\section{Statistical analysis}

All statistical analyses, including propensity score matching analysis, were performed using the $R$ statistical software (version 3.1.0; The R Foundation for Statistical Computing, Vienna, Austria), with $P$ less than 0.05 considered significant. Descriptive statistics, including means and standard deviations, were estimated for both groups. After assessing the normality of the distribution of the tested parameters, between-group differences in continuous variables were assessed using the Student's $t$-test or MannWhitney U-test, as appropriate. Categorical variables, including the proportions of women and those with underlying diseases, were compared in the 2 groups using the $\chi^{2}$ test or Fisher's exact test. The reliability of measurements of distal radius BCT was calculated using the single measures intraclass correlation coefficient (ICC) from a 2-way random effect analysis of variance. For propensity score matching, we used nearest neighbor matching with the caliper 0.25 .

\section{RESULTS}

\section{Characteristics of subsequent DRF patients}

The mean time from initial DRF to subsequent DRF was $121.5 \pm 82.3$ months (range, 1-240 months). Of the 24 patients with subsequent DRF, 16 experienced recurrent DRF of the same wrist, 7 had subsequent DRF on the contralateral side of the initial DRF, and one experienced bilateral DRF simultaneously after an initial unilateral DRF. Patients in the subsequent DRF group were older than those in the initial DRF group, but this difference was not significant $(P=0.091)$. The portion of patients receiving osteoporosis medications was significantly higher in the subsequent than in the initial DRF group ( $41.7 \%$ vs. $19.2 \%, P=0.011)$. Other demographic factors and the proportions of patients with underlying diseases were similar in the 2 groups, except that the rate of asthma was significantly higher in the subsequent DRF group $(P=0.009)$ (Table 1). 
Table 1. Baseline patient characteristics

\begin{tabular}{lccc}
\hline Variables & $\begin{array}{c}\text { Primary } \\
\text { DRF group } \\
(\mathrm{N}=203)\end{array}$ & $\begin{array}{c}\text { Subsequent } \\
\text { DRF group } \\
(\mathrm{N}=24)\end{array}$ & P-value \\
\hline Age $(\mathrm{yr})$ & $64.7 \pm 10.3$ & $68.4 \pm 8.2$ & 0.091 \\
\hline Body mass index $\left(\mathrm{kg} / \mathrm{m}^{2}\right)$ & $23.3 \pm 3.1$ & $23.4 \pm 3.1$ & 0.969 \\
\hline Hypertension & $85(41.9 \%)$ & $9(37.5 \%)$ & 0.681 \\
\hline Dyslipidemia & $84(41.4 \%)$ & $7(29.2 \%)$ & 0.248 \\
Diabetes mellitus & $22(10.8 \%)$ & $3(12.5 \%)$ & 0.734 \\
Stroke history & $12(5.9 \%)$ & $1(4.2 \%)$ & 0.999 \\
Renal insufficiency & $7(3.4 \%)$ & $0(0.0 \%)$ & 0.999 \\
Thyroid or parathyroid disease & $22(10.8 \%)$ & $2(8.3 \%)$ & 0.999 \\
Rheumatoid arthritis & $9(4.4 \%)$ & $1(4.2 \%)$ & 0.999 \\
Asthma & $5(2.5 \%)$ & $4(16.7 \%)$ & $\left.0.009^{\mathrm{a}}\right)$ \\
Malignancy & $21(10.3 \%)$ & $4(16.7 \%)$ & 0.314 \\
Steroid medication history & $11(5.4 \%)$ & $0(0.0 \%)$ & 0.612 \\
\hline Proton pump inhibitor medication & $10(4.9 \%)$ & $3(12.5 \%)$ & 0.146 \\
\hline history & & & \\
Smoking history & $2(1.0 \%)$ & $0(0.0 \%)$ & 0.999 \\
Osteoporosis medication history & $39(19.2 \%)$ & $10(41.7 \%)$ & $0.011^{\text {a) }}$ \\
Vitamin D medication history & $88(43.3 \%)$ & $11(45.8 \%)$ & 0.817 \\
Calcium medication history & $24(11.8 \%)$ & $2(8.3 \%)$ & 0.999 \\
\hline
\end{tabular}

The data is presented as mean \pm standard deviation or number (\%). a) $P<0.05$

$\mathrm{DRF}$, distal radius fracture.

\section{Bone fragility parameters in initial and subsequent DRF patients}

BMDs, TBS, hip geometry parameters, and BCT of the distal radius did not differ significantly in the initial and subsequent DRF groups. The lowest T-score in the DXA, along with BMDs and TBS, were higher-and the rate of osteoporosis was lower-in the subsequent DRF group than those in the initial DRF group. However, the 10-year probability of major osteoporotic fracture in FRAX was significantly higher in patients with subsequent DRF $(7.5 \%$ vs. $10.8 \%, P<0.001$ ) (Table 2). Similar results were observed when propensity score-matched patients with initial DRF and subsequent DRF were compared (Table 3). The ICC was 0.867 (95\% confidence interval, $0.828-0.897$ ) for inter-observer reliability of distal radius BCT.

\section{DISCUSSION}

All subsequent DRFs occurred after minor trauma like initial DRFs, but the characteristics of the initial and subsequent DRFs differed. The age distribution and the periods between initial and subsequent DRFs ranged widely in

Table 2. Bone mineral density, trabecular bone score, hip geometry parameters, cortical thickness of the distal radius and 10 years probability of osteoporotic fracture in patients with primary and subsequent distal radius fracture

\begin{tabular}{|c|c|c|c|}
\hline Variables & $\begin{array}{l}\text { Initial DRF group } \\
\quad(N=203)\end{array}$ & $\begin{array}{l}\text { Subsequent DRF group } \\
\qquad(\mathrm{N}=24)\end{array}$ & $P$-value \\
\hline Lumbar BMD $\left(\mathrm{g} / \mathrm{cm}^{2}\right)$ & $0.910 \pm 0.145$ & $0.918 \pm 0.124$ & 0.682 \\
\hline Femur neck BMD $\left(\mathrm{g} / \mathrm{cm}^{2}\right)$ & $0.742 \pm 0.115$ & $0.748 \pm 0.108$ & 0.835 \\
\hline Trochanter BMD $\left(\mathrm{g} / \mathrm{cm}^{2}\right)$ & $0.618 \pm 0.103$ & $0.639 \pm 0.111$ & 0.369 \\
\hline Total hip BMD $\left(\mathrm{g} / \mathrm{cm}^{2}\right)$ & $0.790 \pm 0.116$ & $0.808 \pm 0.109$ & 0.456 \\
\hline Lowest T score in DXA & $-2.3 \pm 1.0$ & $-2.1 \pm 0.8$ & 0.351 \\
\hline Osteoporosis & $82(40.4 \%)$ & $7(29.2 \%)$ & 0.378 \\
\hline Trabecular bone score & $1.366 \pm 0.082$ & $1.367 \pm 0.090$ & 0.594 \\
\hline $\mathrm{HAL}(\mathrm{mm})$ & $100.9 \pm 5.1$ & $100.6 \pm 4.8$ & 0.762 \\
\hline $\mathrm{NSA}\left(1^{\circ}\right)$ & $125.1 \pm 4.1$ & $125.5 \pm 3.3$ & 0.444 \\
\hline Cortical width (mm) & $4.6 \pm 1.5$ & $4.6 \pm 1.2$ & 0.663 \\
\hline $\operatorname{CSA}\left(\mathrm{cm}^{2}\right)$ & $108.3 \pm 17.3$ & $107.4 \pm 17.8$ & 0.795 \\
\hline CSMI $\left(\mathrm{cm}^{4}\right)$ & $6,969.5 \pm 1,642.5$ & $6,396.1 \pm 1,624.3$ & 0.209 \\
\hline $\mathrm{SM}\left(\mathrm{cm}^{3}\right)$ & $421.1 \pm 87.7$ & $393.4 \pm 97.1$ & 0.149 \\
\hline $\mathrm{BR}$ & $4.1 \pm 1.6$ & $3.8 \pm 1.0$ & 0.580 \\
\hline Mean bicortical thickness of distal radius (mm) & $5.0 \pm 0.9$ & $5.1 \pm 0.8$ & 0.471 \\
\hline 10 years probability of major osteoporotic fracture on FRAX (\%) & $7.5 \pm 4.1$ & $10.8 \pm 4.3$ & $<0.001^{\text {al }}$ \\
\hline 10 years probability of hip fracture on FRAX $(\%)$ & $2.5 \pm 2.7$ & $3.3 \pm 2.6$ & 0.050 \\
\hline
\end{tabular}

The data is presented as mean \pm standard deviation or numbers (\%).

a) $P<0.05$.

BMD, bone mineral density; DXA, dual energy X-ray absorptiometry; HAL, hip axis length; NSA, neck shaft angle; CSA, cross-sectional area; CSMI, crosssectional moment of inertia; SM, section modulus; BR, buckling ratio; FRAX, fracture risk assessment tool; DRF, distal radius fracture. 
Table 3. Bone mineral density, trabecular bone score, hip geometry parameters, cortical thickness of the distal radius and 10 years probability of osteoporotic fracture in propensity score matched patients with primary and subsequent distal radius fracture

\begin{tabular}{|c|c|c|c|}
\hline Variables & $\begin{array}{l}\text { Initial DRF group } \\
\qquad(N=48)\end{array}$ & $\begin{array}{l}\text { Subsequent DRF group } \\
\qquad(\mathrm{N}=24)\end{array}$ & $P$-value \\
\hline Age (yr) & $67.9 \pm 9.2$ & $68.4 \pm 8.2$ & 0.830 \\
\hline Body mass index $\left(\mathrm{kg} / \mathrm{m}^{2}\right)$ & $24.0 \pm 3.3$ & $23.4 \pm 3.1$ & 0.438 \\
\hline Lumbar BMD $\left(\mathrm{g} / \mathrm{cm}^{2}\right)$ & $0.913 \pm 0.135$ & $0.918 \pm 0.124$ & 0.877 \\
\hline Femur neck BMD (g/ $\left.\mathrm{cm}^{2}\right)$ & $0.724 \pm 0.116$ & $0.748 \pm 0.108$ & 0.410 \\
\hline Trochanter BMD $\left(\mathrm{g} / \mathrm{cm}^{2}\right)$ & $0.613 \pm 0.103$ & $0.639 \pm 0.111$ & 0.334 \\
\hline Total hip BMD $\left(\mathrm{g} / \mathrm{cm}^{2}\right)$ & $0.771 \pm 0.121$ & $0.808 \pm 0.109$ & 0.212 \\
\hline Lowest T score in DXA & $-2.4 \pm 1.0$ & $-2.1 \pm 0.8$ & 0.290 \\
\hline Osteoporosis & $17(35.4 \%)$ & $7(29.2 \%)$ & 0.791 \\
\hline Trabecular bone score & $1.352 \pm 0.093$ & $1.367 \pm 0.090$ & 0.313 \\
\hline $\mathrm{HAL}(\mathrm{mm})$ & $101.1 \pm 5.1$ & $100.6 \pm 4.8$ & 0.538 \\
\hline NSA $\left({ }^{\circ}\right)$ & $124.9 \pm 5.0$ & $125.5 \pm 3.3$ & 0.594 \\
\hline Cortical width (mm) & $4.6 \pm 1.7$ & $4.6 \pm 1.2$ & 0.684 \\
\hline $\operatorname{CSA}\left(\mathrm{cm}^{2}\right)$ & $106.6 \pm 17.2$ & $107.4 \pm 17.8$ & 0.856 \\
\hline $\operatorname{CSMI}\left(\mathrm{cm}^{4}\right)$ & $7,018.2 \pm 1,525.3$ & $6,396.1 \pm 1,624.3$ & 0.115 \\
\hline $\mathrm{SM}\left(\mathrm{cm}^{3}\right)$ & $419.0 \pm 77.1$ & $393.4 \pm 97.1$ & 0.227 \\
\hline BR & $4.3 \pm 2.1$ & $3.8 \pm 1.0$ & 0.459 \\
\hline Mean bicortical thickness of distal radius & $4.9 \pm 1.0$ & $5.1 \pm 0.8$ & 0.280 \\
\hline Osteoporosis medication history & $17(35.4 \%)$ & $7(29.2 \%)$ & 0.596 \\
\hline Asthma & $1(2.1 \%)$ & $4(16.7)$ & $0.039^{\mathrm{a})}$ \\
\hline 10 years probability of major osteoporotic fracture on FRAX (\%) & $8.4 \pm 4.3$ & $10.8 \pm 4.3$ & $0.009^{\mathrm{a})}$ \\
\hline 10 years probability of hip fracture on FRAX (\%) & $3.0 \pm 2.9$ & $3.3 \pm 2.6$ & 0.437 \\
\hline
\end{tabular}

The data is presented as mean \pm standard deviation or number (\%).

a) $P<0.05$.

BMD, bone mineral density; DXA, dual energy X-ray absorptiometry; HAL, hip axis length; NSA, neck shaft angle; CSA, cross-sectional area; CSMI, crosssectional moment of inertia; SM, section modulus; BR, buckling ratio; FRAX, fracture risk assessment tool; DRF, distal radius fracture.

these groups, indicating their heterogeneity. In the group comparison between the patients with initial and subsequent DRFs, the bone fragility parameters did not differ significantly. Despite the insignificant differences in bone fragility parameters and higher rates of the administration of osteoporosis medications, the 10-year probability of being affected by a major osteoporotic fracture in the FRAX analysis was significantly higher for patients with subsequent DRF than for those with initial DRF. These findings indicate that the occurrence of subsequent DRF could be dependent on multiple factors rather than those associated with bone fragility alone. Alternatively, bone fragility parameters, especially BMD, may be improved by osteoporosis medications after initial DRF, but other uncorrected or uncorrectable factors such as physical performance level, risk of falling, and sarcopenia may be associated with the development of subsequent DRF.[18-20]

Understanding the characteristics of patients who expe- rience subsequent fragility fractures after initial fragility fractures is necessary to prevent these recurrent fractures. Several studies have evaluated the characteristics of patients who experienced subsequent fractures at other body sites. An evaluation of patients who experienced subsequent hip fracture after initial hip fracture revealed that older age, cognitive impairment, and lower bone mass might increase the risk of subsequent hip fracture.[21] In addition, subsequent vertebral fracture after initial vertebral fracture was associated with pre-existing vertebral deformities, vertebroplasty, and the location of the initial compression fracture.[22-24]

The proportion of patients taking osteoporosis medications was significantly higher in the subsequent than in the initial DRF group. This phenomenon could be explained by the effect of education and emphasis for the evaluation and management of osteoporosis provided by treating physicians after their initial DRF.[7] In addition, the discrep- 
ancies between bone fragility parameters, osteoporosis medication rate, and probability of major osteoporotic fractures in the group comparisons of the initial and subsequent DRF groups could be explained by the FRAX calculation method. FRAX reflects the results of various variables including bone fragility parameters and clinical situations.[11] Although each parameter did not show significant differences in the group comparisons, the combinations of these factors could reveal significant differences.

This study has several limitations. First, its retrospective design limited its ability to prove causality for the occurrence of subsequent DRF. In addition, we could not evaluate other factors that may be related to the occurrence of subsequent DRF, such as physical performance level, risk of falling, and sarcopenia. A prospective observational study would be more suitable, but the time from initial to subsequent DRF was long and variable, and the incidence of subsequent DRF was not high. Thus, collecting a sufficient number of patients with detailed information would be difficult. Second, our institution is a tertiary referral hospital; thus, these subjects may be more diseased or injured than those in other institutions. Third, all study subjects were of Korean ethnicity. Because some hip geometry parameters, including HAL and NSA, vary according to ethnicity, the results cannot be extrapolated to other populations.[25] Finally, although we used propensity score matching to overcome the imbalances between the 2 groups, only 24 patients had experienced subsequent DRF, a much smaller number than the 203 for patients with initial DRF.

In conclusion, patients with subsequent DRF showed heterogeneity with respect to the age distribution and time interval between initial and subsequent DRF. Bone fragility parameters did not differ significantly between patients with initial and subsequent DRF. However, the ten-year probability of being affected by a major osteoporotic fracture was significantly higher for patients with subsequent DRF despite a higher number of osteoporosis treatments being performed in patients with subsequent DRF. These findings suggest that the occurrence of subsequent DRF after initial DRF can be attributed to multiple factors rather than bone fragility alone. Systematic and multidisciplinary management would be helpful for preventing the occurrence of subsequent DRF after the initial DRF.

\section{DECLARATIONS}

\section{Funding}

This study was supported by a research fund (2020IT00011) from Asan Institute for Life Science, Asan Medical Center, Republic of Korea.

\section{Ethics approval and consent to participate}

Ethics approval and consent to participate: This study was approved by the Institutional Review Board of Asan Medical Center (2019-0686) and informed consent was waived.

\section{Conflict of interest}

No potential conflict of interest relevant to this article was reported.

\section{ORCID}

Jae Kwang Kim https://orcid.org/0000-0001-5104-4634 Minyoung Oh https://orcid.org/0000-0002-6840-3215

Young Ho Shin https://orcid.org/0000-0002-9388-9720

\section{REFERENCES}

1. Balasubramanian A, Zhang J, Chen L, et al. Risk of subsequent fracture after prior fracture among older women. Osteoporos Int 2019;30:79-92. https://doi.org/10.1007/ s00198-018-4732-1.

2. Haentjens $P$, Autier $P$, Collins J, et al. Colles fracture, spine fracture, and subsequent risk of hip fracture in men and women. A meta-analysis. J Bone Joint Surg Am 2003;85: 1936-43. https://doi.org/10.2106/00004623-20031000000011.

3. Chung KC, Shauver MJ, Birkmeyer JD. Trends in the United States in the treatment of distal radial fractures in the elderly. J Bone Joint Surg Am 2009;91:1868-73. https://doi. org/10.2106/jbjs.H.01297.

4. Nevitt MC, Cummings SR, Stone KL, et al. Risk factors for a first-incident radiographic vertebral fracture in women $>$ or $=65$ years of age: the study of osteoporotic fractures. J Bone Miner Res 2005;20:131-40. https://doi.org/10.1359/ jbmr.041003.

5. Crandall CJ, Hovey KM, Cauley JA, et al. Wrist fracture and risk of subsequent fracture: Findings from the women's health initiative study. J Bone Miner Res 2015;30:2086-95. 
https://doi.org/10.1002/jbmr.2559.

6. Barrett-Connor E, Sajjan SG, Siris ES, et al. Wrist fracture as a predictor of future fractures in younger versus older postmenopausal women: results from the National Osteoporosis Risk Assessment (NORA). Osteoporos Int 2008;19:60713. https://doi.org/10.1007/s00198-007-0508-8.

7. Shin YH, Hong WK, Kim J, et al. Osteoporosis care after distal radius fracture reduces subsequent hip or spine fractures: a 4-year longitudinal study. Osteoporos Int 2020;31: 1471-6. https://doi.org/10.1007/s00198-020-05410-3.

8. Schuit SC, van der Klift M, Weel AE, et al. Fracture incidence and association with bone mineral density in elderly men and women: the Rotterdam Study. Bone 2004;34:195-202. https://doi.org/10.1016/j.bone.2003.10.001.

9. Nguyen BN, Hoshino H, Togawa D, et al. Cortical thickness index of the proximal femur: A radiographic parameter for preliminary assessment of bone mineral density and osteoporosis status in the age 50 years and over population. Clin Orthop Surg 2018;10:149-56. https://doi.org/10.4055/ cios.2018.10.2.149.

10. Shah GM, Gong HS, Chae YJ, et al. Evaluation and management of osteoporosis and sarcopenia in patients with distal radius fractures. Clin Orthop Surg 2020;12:9-21. https:// doi.org/10.4055/cios.2020.12.1.9.

11. Kanis JA. Assessment of osteoporosis at the primary health care level: WHO collaborating centre for metabolic bone diseases. Sheffield, UK: University of Sheffield; 2008.

12. World Health Organization. Assessment of fracture risk and its application to screening for postmenopausal osteoporosis. Report of a WHO Study Group. World Health Organ Tech Rep Ser 1994;843:1-129.

13. Uusi-Rasi K, Semanick LM, Zanchetta JR, et al. Effects of teriparatide [rhPTH (1-34)] treatment on structural geometry of the proximal femur in elderly osteoporotic women. Bone 2005;36:948-58. https://doi.org/10.1016/j.bone.2005. 03.003 .

14. Beck TJ, Looker AC, Ruff CB, et al. Structural trends in the aging femoral neck and proximal shaft: analysis of the Third National Health and Nutrition Examination Survey dualenergy X-ray absorptiometry data. J Bone Miner Res 2000; 15:2297-304. https://doi.org/10.1359/jbmr.2000.15.12.2297.

15. Kim KM, Lim JS, Kim KJ, et al. Dissimilarity of femur aging in men and women from a Nationwide Survey in Korea
(KNHANES IV). J Bone Miner Metab 2013;31:144-52. https: //doi.org/10.1007/s00774-012-0386-9.

16. Webber T, Patel SP, Pensak M, et al. Correlation between distal radial cortical thickness and bone mineral density. J Hand Surg Am 2015;40:493-9. https://doi.org/10.1016/j.jhsa. 2014.12.015.

17. Schuind FA, Linscheid RL, An KN, et al. A normal data base of posteroanterior roentgenographic measurements of the wrist. J Bone Joint Surg Am 1992;74:1418-29.

18. Kelsey JL, Prill MM, Keegan TH, et al. Reducing the risk for distal forearm fracture: preserve bone mass, slow down, and don't fall! Osteoporos Int 2005;16:681-90. https://doi. org/10.1007/s00198-004-1745-8.

19. Janssen I, Heymsfield SB, Ross R. Low relative skeletal muscle mass (sarcopenia) in older persons is associated with functional impairment and physical disability. J Am Geriatr Soc 2002;50:889-96. https://doi.org/10.1046/j.15325415.2002.50216.x.

20. Cho YJ, Gong HS, Song CH, et al. Evaluation of physical performance level as a fall risk factor in women with a distal radial fracture. J Bone Joint Surg Am 2014;96:361-5. https: //doi.org/10.2106/jbjs.L.01359.

21. Egan $M$, Jaglal S, Byrne $K$, et al. Factors associated with a second hip fracture: a systematic review. Clin Rehabil 2008; 22:272-82. https://doi.org/10.1177/0269215507081573.

22. Lunt M, O'Neill TW, Felsenberg D, et al. Characteristics of a prevalent vertebral deformity predict subsequent vertebral fracture: results from the European Prospective Osteoporosis Study (EPOS). Bone 2003;33:505-13. https:// doi.org/10.1016/s8756-3282(03)00248-5.

23. Lee $K A$, Hong $S$, Lee $S$, et al. Analysis of adjacent fracture after percutaneous vertebroplasty: does intradiscal cement leakage really increase the risk of adjacent vertebral fracture? Skeletal Radiol 2011;40:1537-42. https://doi.org/ 10.1007/s00256-011-1139-x.

24. Han SL, Wan SL, Li QT, et al. Is vertebroplasty a risk factor for subsequent vertebral fracture, meta-analysis of published evidence? Osteoporos Int 2015;26:113-22. https:// doi.org/10.1007/s00198-014-2848-5.

25. Broy SB, Cauley JA, Lewiecki ME, et al. Fracture risk prediction by non-BMD DXA measures: the 2015 ISCD official positions part 1: Hip geometry. J Clin Densitom 2015;18:287308. https://doi.org/10.1016/j.jocd.2015.06.005. 
